\title{
Discussion on the Construction and Management of University Laboratory
}

\author{
Ruiying Xu \\ Baicheng Normal College, 137000
}

Key Words: University Laboratory; Construction and Management.

\begin{abstract}
The laboratory plays a very important role in teaching of colleges and universities. Its construction and management urgently need to raise a level. Laboratory of colleges and universities is very important place where cultivating high-tech talents and creative spirit. It is also an important base for scientific research and teaching. The stand or fall of lab management, can directly affect the process and quality of experimental work. In the construction of colleges and universities, laboratory is playing more and more obvious function, just as Professor Weichang Qian, academician of Chinese Academy of Sciences and famous physicist, said "Laboratory is the heart of the education of colleges and universities, who directly concerns the development and survival of colleges and universities". So, it is a laboratory management problems worthy to be discussed that perfectly establishing an effective laboratory management system to improve the quality of practice teaching.

The construction and management of laboratory is an important part of college and university work. The experimental teaching is also an important step of the teaching system in colleges and universities. It has an important theoretical and realistic significance for abundantly giving play to the effect of the modern education means and utilizing lab teaching to cultivate talents with high practice ability that discussing on the pattern of university laboratory construction and management. In this paper, the current problems and countermeasures of our college laboratory construction and management are briefly discussed.
\end{abstract}

\section{The Problems Existing in the Construction and Management of Laboratory}

First, lack of scientific construction and management of the laboratory. Since entering the 21st century, the laboratory construction in China has achieved development by leaps and bounds. It also has emerged a large number of laboratories with strong scientific research strength and content of science and technology. Some of them even are in a leading position in the world. However, with the enrollment expansion of colleges and universities and the gradual improvement of the society for talents requirement now, at present, a lot of university laboratory construction and management can't meet the need of talent cultivation. Many laboratories of colleges and universities are facing with current situation that experimental apparatus are backward, laboratory rooms and assorted equipments are hysteretic, especially in scientific construction and management of laboratory, it couldn't keep pace with the times. This has led to the laboratory teaching can't achieve the purpose that students applying their knowledge and theory teaching combining with practice in the limited space. It has affected the training of high-quality talents in colleges and universities.

Second, lack of comprehensiveness and innovativeness for experiment content. Comprehensiveness and innovativeness talents are the requirement and goal of talent cultivation in the 21st century, and laboratory teaching is an important part of the modern personnel training. But now, in many of laboratory teaching activities of colleges and universities, operability and confirmatory experiments still are major. So, students are limited in the framework made by teachers, and can only do experiments in accordance with the steps designed well, that greatly restricted the improvement of their creative thinking ability. Now, although most of the laboratory teaching activities embody their professional and practical, lack of comprehensive and innovativeness. Often experimental teaching embodies its professional and practical, but lack of comprehensive and innovativeness. Frequently, a laboratory is only open for a single course or 
major, while each of them also lack of contact. That leads to a comprehensive teaching difficult to achieve and experimental course lack of flexibility. At last, it is disadvantage of cultivating students' innovative thinking.

Third, laboratory managers lack relevant knowledge. With the further deepening of reform and innovation of education teaching system in colleges and universities, faculties has been further improved. But it doesn't be received enough attention that the cultivation and introduction of laboratory management personnel. So laboratory managers' degrees are generally low. That leads to most of laboratories now lack of staffs possessing professional or related professional knowledge to manage and maintain equipments. Its main reason is that colleges and universities do not enough attach importance to laboratory management. The laboratory management of many universities is only relied on ordinary security guards to take into account. But, the maintenance routine and examination of many instruments can't be provided by these staffs. It leads to laboratory equipment and facility maintenance low efficiency, loss too fast. That has caused considerable wasting of resources. At the same time, due to the lack of manager regulatory consciousness, the experiment equipments (especially some small instruments or consumables) often also are made lost.

Fourth, the management methods are backward, and they can't organically combine with information construction. The maintenance rate of laboratory equipments is low, and storage and management of experiment materials are not in place. These problems not only are caused by unreasonable management structure, but also is one of the consequence s of laboratory management regulations backward. First of all, some correlative systems are imperfection. For instance, "The Laboratory Instruments and Equipments Management and Method Of Application”, “The Laboratory Security System", "The Laboratory Accident Liability and Damage and Loss Compensation System"; Secondly, laboratory information, including equipments, teaching experiments and research topics, research results and other information, has some characteristics like large in quantity, widespread, change more frequently, urgent communication. The traditional laboratory management methods can't meet the requirements of modern laboratory. At present, many colleges and universities laboratory management fails to be combined with information construction in colleges and universities, and fails to realize computer management, laboratory equipments also fail to put on digital records. These problems make overall efficiency of laboratory management low, and there is a certain distance from the goal of construction of standardized laboratory.

Fifth, laboratory management supervision work is not in place. The supervision work, not only is an important link to ensure the quality of the experiment, and is also the important means to ensure laboratory quality meeting the requirements of teaching and scientific research, but also a difficult point for laboratory management. Currently, colleges and universities laboratory management is facing with this present situation that lack of sound laboratory supervisory system, and the supervision work is not in place. Due to the lack of effective supervision, many experimental activities fail to reach the desired effect, and it is also not in place for laboratory equipment maintenance and safekeeping.

\section{The Suggestions of University Laboratory Construction and Management}

First, enhance the recognition degree of laboratory construction and management. Firstly, determine the necessity and importance of the laboratory construction and management. Specifically, they should do that: first, increase the investment in laboratory construction, improve comprehensive from the hardware facilities and create a good laboratory environment for persons with comprehensive and innovative ability; Second, further improve the system of laboratory management and determine laboratory management goal; Three, establish a laboratory management performance indicators system, determine experimental teaching task; increase the intensify laboratory opening, and improve the innovativeness and comprehensiveness of experimental teaching.

The management systems, are the basis of lab management and important guarantee that experimental work can be carried out smoothly and orderly, and they are rules and regulations must 
be abided. To make the management institutionalization, standardization and scientific, they must establish a set of effective rules and regulations, such as "Laboratory Managers Regulation”, "The Laboratory Safety Regulation”, “The Instruments and Equipments Management Regulation”, “The Registration System of Borrowing Equipments" and so on. Simultaneously, strictly according to the requirements of the system, we should regularly check the condition observing the system. On this account, they check and assess the experimental staffs. At work, they should definite the responsibility of the laboratory technician, and rules and regulations should be categorized to each chamber in the laboratory room, make the person be clear at a glance. Rules and regulations in the process of execution need to be constantly improved and perfected. Problems found should be in time amended. The normative systems not only can play good restrictive function to lab managers and all users, but also can help go head smoothly to the experimental teaching.

It is relatively complicated for the management of the laboratory instruments and equipment. But, more complicated, it should be taken more seriously and formulate good management styles. So the laboratory staffs should establish the whole files of instruments and equipments, on the basis of setting up more equipment files. Establishing a complete file, can make managers know the amount of their own instruments and equipments. Establish a complete file, allows managers to manage their own experiment equipment well. Only doing well in management for lab equipment maintenance, storage, and use, can ensure the normal work of the experiment.

Due to Laboratory used more frequently, many students come and go, and a large number of valuable instruments and important data stored in the lab, it is necessary that doing a good job in safety management. In the usual storage and using process, laboratory instruments and equipments should be attached importance to their safety and protection, to avoid accidents happening. Experimental staffs should record the detailed results of the usual management work for later examination, such as the experimental instruments and equipment purchase, leave records, equipment operation and maintenance records, inspection records, the experimenter posts log, and so on. It is to create favorable conditions for laboratory to the regularized management.

Second, strengthen the construction of experiment teaching staffs. On the one hand, colleges and universities should strengthen training of laboratory management staffs and the introduction of high-quality laboratory management personnel, and further improve the laboratory management personnel's professional skills and academic requirements; On the other hand, the talent structure should be improved. the experiment teaching staff management ability of professional management and technical management ability, improve the proportion of highly educated personnel. At the same time, also shall establish a sound system of laboratory personnel performance management, and develop a feasible assessment scheme, that through examining, evaluating, rewarding the good and fining the bad, fully arouse the enthusiasm of laboratory personnel.

Strengthen management and improve the experimental technical personnel's professional quality. Experimental staff's daily work should firstly cooperate with teachers to do well the preparatory work for the students' experiment. And secondly, experimental staff should do well the experiment instrument maintenance and site health and safety management, to ensure that the experiment can be completed smoothly and effectively. Only enhancing the quality of the experimental technical personnel and improving the management level, can it improve the experimental teaching quality.

Firstly, experimenter themselves must strictly observe everything that the school all rules and regulations, definite their own scope of work and responsibilities and devote herself to the rigorous work style to the construction, use and management of laboratory, at last complete tasks with good quality. Experiment staffs, at the early stages, should fully understand the experiment content and the teachers on experiment requirements given, so that they can timely and accurately prepare the early work. In the experimental process, they should record the problems and timely correct them. After finishing the experiment, experimenter should timely maintain the experiment instruments, equipments and environmental health, work for the next experiment on the rails. Secondly, the experiment staff should pay attention to improve their business level, often modestly consult predecessors and read more professional books, constantly enrich and improve themselves ability. Of course, when the experiment staff improving their ability actively, if the school could actively 
create conditions and send out the experiment staff, they can grasp proficiency business skills and improve their work ability, work methods and management level, which is conducive to the development of experiment teaching. At the same time, the researchers should strengthen their professional ethics and ideological and political quality and set up the correct outlook on life and values. It is necessary that there is a correct outlook on life and values. As an experimental manager, he (she) should be for all students, for everything of students, and do their job well. Continuously explore, learn and improve themselves' comprehensive qualities.

Third, make full use of modern management means. The completed campus network brought by computer network technology, no doubt provides an unprecedented good opportunity for complicated laboratory management. The networked and computerized management can greatly improve the efficiency of laboratory management, and realizing the laboratory network is also one of the goals of the modern university laboratory construction. At the same time, the digital platform established through the network management means, can aim at the characteristics, that currently laboratory teaching data exchange is frequent and information is large, to design experiment and course tutorial. It is beneficial to the development of the modern comprehensive talent.

Combine organically some laboratory whose features similar, carry out some experimental teaching research work, strengthen scientific research cooperation among each subjects, to realize resources sharing between laboratories. Many laboratories are divided according to their respective majors, less collaboration with each other. While each laboratory instruments configuration is all in readiness, it leaded to high investment of the equipment in each department and more repeated input device. The utilization rate some equipment in a certain department is not high. These caused great waste of resources. Moreover, effective integration of resources can make full use of existing equipment. The establishment of a good management team and a set of scientific and effective management mode, can make full use of limited funds to purchase equipments be used between different departments, achieving the purpose of sharing resources. It is very significant to improve all aspects of this level and work efficiency. Firstly, scientific management mode can improve the work efficiency. Secondly, making resource integration to the extra laboratory can save manpower, space, and fully play the role of each staff. That can improve the overall level and quality of experiment teaching team. The sharing model of laboratory resource also can make everyone exchange experience in the learning. That is beneficial to the construction of the experimental technical team, and improving the level of experimental teaching.

It is an important task to improve the quality of the experiment that put laboratory management work into effect. A manager should take laboratory itself unique characteristics seriously, change some old ideas and comply with the development of era. In short, while laboratory management work looked like simple, yet it is very complicated. We should innovate boldly, establish management mode suitable for this unit and create a good work and learning environment, cultivate more practical talents.

In a word, the experimental teaching is inseparable organism from the teaching work. It is also advocated by the new standard. The establishment of a good experimental teaching management system can provide a platform to explore for the reform of the course system and content of experimental teaching. The laboratory construction and management also need to adapt to the Times and explore and innovate actively and boldly to scientific management methods.

\section{The Laboratory Construction and Management Research of College of Communication}

With the New Media Age of integration of three networks arrival, the higher education team of media is growing stronger and stronger. It has become a hot topic that how to effectively manage media laboratory in colleges and universities to make it adapt to the rapid development of the media industry. From three aspects that characteristics, present situation and countermeasures of the media lab, combine with the present situation of college laboratory to bring forward opinions.

I . The characteristics of media laboratory 
i . The cost is high, the specialized laboratory infrastructure, equipment, updated quickly, the early stage of the media laboratory construction need to invest a lot of money, site location, spatial size, need to be considered repeated proof. Due to taken in the field of radio, film and television, recording, editing and broadcasting and other professional knowledge, such as virtual studio, professional performing arts center, exhibition hall, etc to decorate all need to achieve professional standards, some equipments such as the professional cameras, recording equipments, need to be imported from abroad with expensive cost.

ii. Sharing and openness make management difficult. Because the media major having characteristic of subject overlapping, communication laboratories usually have characteristic of multiple professional sharing media laboratory. Such as producer director major, camera shooting major, broadcasting and hosting major and so on, all need to conduct later stage compilation for material. It has increased the difficulty of management and deployment.

iii. Practice teaching form is special. The media major is the subject that skillfully fused by the media art and technology in together. So, it has the characteristics of the experimental teaching itself. It also raises student's manipulative ability, artistic innovation ability, as well as the practical results show ability. It cultivates outstanding talents for the professional media culture in China.

II. The current situation and problems of media laboratory construction and management

At present, China's media laboratory construction has been preliminary obtained the scale accomplishments. There are some representative accomplishments, such as "The Experimental Teaching Demonstration Center of Wuhan University", the first national media experimental teaching demonstration center among Chinese comprehensive university. The Communication University of China (CUC), the typical representative junior colleges, has two national experimental teaching demonstration centers and six experimental teaching demonstration center in Beijing. We has been put editorial office, studio and photo studio into use in our laboratory. Class from the above data we can see the degree of emphasis to media lab has been improved obviously. But now, more and more graduates of the university entrance exam to join the media professionals. The media laboratory construction and management still exist many problems, mainly include the following:

$i$.The degree of emphasis to media laboratory construction and management is insufficient, and the input intensity of equipments and capitals is lower.

The scale of students major in media is constantly growing. But, the per capita resource of experimental teaching in many colleges and universities has not got obvious growth. Some colleges and universities lack of equipment, even borrowing the adjacent lab to conduct the practice teaching. It has influenced seriously the scientific and systematic of students' practice course. There are also some schools whose equipments outdated. They use the eliminated experiment device and content to teach students, that has made students' skills of experiment and operation cannot adapt to the rapid development of media industry.

ii . The position is not accurate, and lack of certain forward-looking

From the function, media laboratories can be divided into the basic laboratories, professional laboratories and comprehensive laboratories. The basic laboratories provide experimental environment for basic computer experiment teaching and cultivate the basic experiment platform for talents with practical ability in media industry. The professional laboratories are important places where students are trained innovative quality and show their ability. The comprehensive laboratories are integrating production, study and research, so as to promote coordinated development laboratory, for the purpose of the three students to participate in research projects, for the media provide powerful talent guarantee of the project of business cooperation. At present, most of the media labs position is not accurate and cannot make the best use of them.

iii. The manager team construction is not perfect, and management system is imperfect.

Because of the traditional reason that colleges and universities attaching great importance to scientific research, the laboratory work is considered to be a kind of ancillary work. Universities and colleges tend to the development of the teaching team, while ignore the laboratory team 
construction. So it is difficult to arouse the enthusiasm of experiment personnel, and it is also hard to attract excellent talents into the experiment technology team. In addition, due to less quantity of full-time experiment personnel in colleges and universities, an experimenter manager usually manages several laboratories. So their working pressure is bigger. According to the statistics, the number of on-the-job experiment personnel is lower than standard now in China. The managers who have graduate degrees are only one-tenth of the teacher team.

III The countermeasure research on the construction and management of media laboratory

$i$. Increase the vigor of investment and construction and various channels to raise funds

Media lab should innovative operation mode on the basis of the original allocate funds, such as imitation media group management mode, through contract or cooperate with enterprises, the media, exercise the management ability of students, expand sources of funds in the lab. The colleges also encourage the use of lab resources to carry out the activities. Using equipments provided by laboratory produce and broadcast a variety of programs and campus news. Through this platform, the colleges attract advertisers.

ii. Strengthen information management, open and share laboratory equipment

Opening and sharing not only are confined to the form, in addition to experimental site, open space to the teachers and students, instruments and equipments also need opening and sharing. In particular, it need to introduce information management system, strengthen the equipment function module integration, open sharing for instruments and equipment specifications, performance parameters, use state, borrow, open and transparent and implement dynamic management. They need to implement the advanced thought of "interdisciplinary" to the construction of the laboratory to promote the common progress of the whole school related field.

iii. Strengthen the mechanism reform to staff management training and stimulating

On the lab management aspect, talent is the core. It is the basic guarantee to improve the quality of laboratory work that developing a good quality, strong sense of responsibility, reasonable structure and high level of experimental team. On the basis of guarantee teachers team construction, they need absorb highly-educated and high-quality talents or elites introduced from the media industry, and make the corresponding encouragement and recognition to excellent laboratory staff by means of establishing and perfecting the staff performance appraisal, assessment and awarding systems. It will create a new situation that laboratory staffs work hardly.

In a word, the quality of laboratory construction and management directly affects the realization of the integration of production, study and research in colleges and universities. However, from the current situation to see, there are many problems in the process of colleges and universities laboratory construction and management. If colleges and universities want to further improve the level of teaching and scientific research, they must strengthen and improve the laboratory construction and management.

\section{References:}

[1]XIE Xiao-hong,BAO Qiu-yan,BAO Ri-yang.Exploration and Thinking of Opening Experiment Teaching and Management[J];Laboratory Science, 2011,5 .

[2] WANG Gui-cai, YANG Jiu-min. On Laboratory Opening [J] Research and Exploration in Laboratory,2011,9.

[3] YI Kun-nan,YU Fei-fei. Cultivating the Creative Ability of Students in the Comprehensive and Design Type of Experiments[J] The Experimental Technology and Management, 2007,8.

[4] YANG Xiao-Xian,YAN Guo-ping,ZHAO Yun-di,Chen Shi ping. Reform and practice of managing system of electrician \& electron teaching experiment center[J] The Experimental Technology and Management,2007,7.

[5] XIE Zhu-lan. Reforming Experimental Teaching to Cultivate Students' Practical Ability and Creativity[J] Research and Exploration in Laboratory,2007,6.

[6] DIAO Ming, WANG Song- wu.Experience on the construction of the experiment education demonstration center-the "eight combinations"[J] The Experimental Technology and Management, 2006,9. 